\title{
GOLD DECORATED TEETH FROM THE PHILIPPINE ISLANDS ${ }^{1}$
}

\author{
LESLIE F. RITTERSHOFER, D.D.S., M.S. \\ Ann Arbor, Michigan
}

While making a series of measurements to determine changes in the face and jaws on skeletal material in the Philippine collections of the Museum of Anthropology at the University of Michigan, it was learned that this collection contained a group of 43 human anterior teeth with small holes on the labial surface into which gold discs or plugs were inserted for decorative purposes. These examples of an unusual method of adornment were obtained by the 1922-1925 archaeological reconnaissance expedition sent by the University, under Dr. Carl E. Guthe, to the southern half of the Philippine archipelago. They were originally associated with burials located in three widely separated parts of the Visayan, or central, group of islands, namely the islands of Negroes, Masbate, and Samar. Regarding conditions associated with these finds, Dr. Guthe states,

"The great majority of the teeth bearing gold decorations was encountered while screening the deposits in two burial caves on small islands just off the west coast of Samar. The conditions and associations in both, which were in limestone formations, were essentially the same. The floors, although usually dry, had clearly been subjected to water action, probably during storms. The confusion resulting from natural disturbances was increased by visits of beasts and men. The bones of the skeletons had been scattered. The caves had apparently been used a long time as places of burial, for the collections, obtained largely by screening the deposits, included, in addition to the ornamented teeth and other skeletal remains, the following materials: fragments of stoneware and earthenware plates and bowls; sherds of greenish-brown glazed jars and of nativeware vessels; a few iron implements and handles made from antler fragments; and articles of adornment, including bracelets, rings, and beads of shell,

1 Presented at the Thirteenth General Meeting of the International Association for Dental Research, Chicago, March 16-17, 1935; J, Den. Res. 15: 158, 1935. 
stone, and gold. It may be noted in passing that some of the associated Chinese trade vessels found with the teeth appear to have been made during the Sung dynasty (960-1279 A. D.). Among the hundreds of disassociated human teeth were many that were discolored, probably largely by betelnut stain. Others showed evidence of having been filed, either to a point, or to flatten their labial surface."

Documentary evidence shows that the Filipinos decorated their teeth not many centuries ago. Antonio Pegafetta, Italian chronicler of Magellan's voyage, records having seen a native chief with gold spots on every tooth. ${ }^{1}$ Senilla, in 1564-5, mentions a custom of decorating teeth with gold. ${ }^{2}$ Pedro Chirino's "Relacion," published in Rome in 1604, describes the Filipinos' custom of staining and decorating their teeth with gold discs. ${ }^{3}$ Morga, in 1609, also mentions this custom. ${ }^{4}$ Father Diego de Bobadilla, in an unsigned and undated manuscript probably written in the years 1638-1640, wrote that the Filipinos cover the teeth with a black and glossy or flame colored polish; and thus their teeth become black, or as red as vermillion. In the upper row they make a little opening, and fill it with gold, which shows off to advantage on the black or red background of that polish. ${ }^{5}$

The writings of Juan Francisco de San Antonio, published in Manila between 1738 and 1744, seem to indicate that the Filipinos in general abandoned the custom before the middle of the eighteenth century. ${ }^{8}$ The records of Dr. Louis Ottofy of Chicago indicate that a modified form of this peculiar type of adornment still persisted occasionally as late as the twentieth century. ${ }^{7}$ Yet the custom of mutilating teeth for purposes of adornment seems to have disappeared in the Philippines before any known careful record was made of the process by which disfigurement was accomplished. Fortunately, travellers of recent years in other islands of Malaysia have described a still existing identical custom among the inhabitants of Borneo and Sumatra, with

1 Blair and Robertson 33, 123.

${ }^{2}$ Ibid. 2, 223.

Ibid. $12,187$.

I Ibid. 16, 78.

Ibid. 29, 287.

- Ibid. 40, 327 .

'Personal communication to Dr. Guthe. 
the single difference that brass was used instead of gold. $8,9,10,11,12,18,14$ Furness describes such a custom among the Ibans of Borneo."

The custom of mutilating teeth for purposes of adornment is not confined to Malaysia. A variety of forms of tooth filing occur in many parts of the world. In New Guinea the natives file the teeth to points. ${ }^{15}$ In central Africa filing to other forms is practiced. ${ }^{16}$ At least two forms of tooth filing existed in Mexico, Central America, and various parts of South America. ${ }^{17}$ But the custom of inlaying teeth, as described in this paper, is by no means so wide in its distribution. The only parts of the world outside of Malaysia in which it occurs are southern Mexico, northern Central America, and northwestern South America (Ecuador). ${ }^{18}$ In these regions, the drilled holes were often of larger diameter than those here described, and in addition to gold the Indians used polished stones and ores as material for the plugs.

The large University of Michigan collection of teeth from the Philippines bearing gold discs or holes for their insertion warrants a detailed technical examination of the specimens in order to determine: (1) methods used in carrying out the operative procedures preliminary to actual insertion of the discs; (2) exact method of attachment; (3) character of the metal used; (4) shape in which the metal was available; (5) reason for the stains; (6) effects which such mutilation may have had upon the teeth themselves, the underlying pulps, and the surrounding soft tissues and bone; and (7) the effect of diet and the presence or absence of any methods of oral hygiene practiced.

Fig. 1 is a photograph of each tooth from the labial aspect. Fig. 2 is an $\mathrm{x}$-ray from the mesio-distal aspect. The teeth are arranged in the same order in both figures, starting with no. 1 at the

J. B. Davis, 289 . Skull no. 279.

${ }^{2} \mathrm{H}$. Ling Roth 2, 78.

${ }^{10}$ E. H. Gomes, 38.

${ }^{11}$ W. H. Furness, p. 157.

18 Alfred Maas 1, 150.

$12 \mathrm{Ibid} .373$.

${ }^{14}$ von Nehring, p. 217.

${ }^{15}$ Bene van Rippen, 4.

${ }^{15}$ Bene van Rippen, 2.

${ }^{17} \mathrm{M}$. H. Saville; Bene van Rippen, 1 and 3.

${ }^{18}$ Ibid. 
upper left. A few examples among these of conditions bearing on the questions raised will be discussed. Tables I and II summarize the conditions and characters observed on each tooth. In order to avoid undue repetition, it may be said that with but one or two exceptions all the teeth are stained a light brown, presumably from the chewing of betel nuts. The anterior teeth, for the most part, have strong marginal ridges on the lingual surface, creating a modified shovel effect. Concretions, mostly of the salivary type, are present in almost every case. More or less severe abrasion of the occlusal surface of the teeth is nearly always present.

Nos. 3, 6, 18, 24, and 39 illustrate the various designs found. These vary from a single hole to five, six, or seven, sometimes arranged in a triangular pattern. Nos. 4 and 11 illustrate the two types of plate patterns found. One is cut in the shape of a four leaf clover; the other is simply an irregular thin plate of gold.

Figs. 1 and 2 illustrate a number of conditions found frequently. For example, the first tooth on the upper left (No. 1), an upper central incisor, shows the distribution of stain characteristic of many of these teeth; the labial surface is quite free from stain for perhaps $3 \mathrm{~mm}$. from the cemento-enamel junction. This condition would indicate that a marked marginal gingivitis ${ }^{19}$ had existed previous to staining of the teeth. In this tooth only one of the six holes contains a metal disc, which in this case is semi-circular. The $\mathrm{x}$-ray of this tooth (No. 1, fig. 2) indicates that the base of the disc barely rests in the dentine and that the pulp apparently had undergone considerable recession..$^{20}$

No. 2 is a canine with extremely heavy deposits which extend apically below the cemento-enamel junction, so that considerable recession of the gums must have occurred. Both $x$-ray and photograph show the extreme abrasion of the occlusal surface.

No. 3 , an incisor, illustrates a condition consistently present, namely, the hole is round and has a round base. In this particular case there is nearly a pulp exposure (fig. 2). The distribution of the stain indicates that a marked marginal gingivitis existed.

No. 4 is an upper left canine, the entire labial surface covered by a thin sheet of gold measuring but $0.15 \mathrm{~mm}$. in thickness. Upon removal this sheet or plate showed no evidence of cementation; but the under surface was found to be in the form of a short gold tube, broken open at the pulpal end, and apparently formed by punching a small gold rod into the plate directly over the hole. The split open end of the tube indicates this method of attachment. The labial surface was smoothed off and highly polished.

No. 8 is an incisor illustrating a common condition: the primitive operator drilled through enamel and dentine into the pulp. Fig. 2 indicates this condition very clearly. The slight flange on the labial side of the disc shows that it had been hammered into the hole. This tooth is a striking illustration of decorative filing. Both mesial and distal corners are filed, giving the crown a V-shaped appearance. Nos. 16, 23, and 42 show crowns also filed V-shaped.

19 Kronfeld, R. 291, 305.

${ }^{20}$ Kronfeld, R. 35. 
No. 9 is a lateral incisor with a variation in form commonly known today as a peg lateral. The contact points are excessively worn by long hard usage in mastication.

No. 11 is an incisor covered by one of the four-leaf patterns of gold plate. The plate in this case is much thicker $(0.33 \mathrm{~mm}$.) than the one on no. 4 , and was secured by the same method, except that in this case the hole was carried completely through the pulp chamber and ends in the opposite wall ( $f i g .2$ ), probably not a painless operation. The great size of the pulp chamber indicates early death of the tissue. ${ }^{21}$

No. 15 shows another example of probable gingivitis, the stain being high off the cemento-enamel junction. In this case the incisal edge is so severely abraded that two of the decorative holes have been opened from the occlusal.

No. 16, an incisor with the crown filed V-shaped, has a single large hole which, though indistinctly shown in fig. 2, penetrated the pulp chamber. The root apex shows considerable hypercementosis. A marked hypercementosis may also be observed on the apices of nos. 23,29 , and 36 .

No. 18 is an incisor illustrating apical absorption and hypercementosis. It has three labial holes which are shallow and hold no gold. The pulp chamber had been opened from the lingual surface by a large hole. One may speculate as to whether the hole might have served to drain an abscess. The conditions indicate the presence of infection and the location of the hole contraindicates any decorative purpose. ${ }^{22}$

Nos. $5,8,11,16$, and 23 in $f i g .2$ are teeth in which the pulp chamber was penetrated by the decorative hole. In no. 23 , the large size of the pulp and the small, slightly worn contact points, indicate that the tooth was yet young when lost by infection. ${ }^{23}$

No. 24 is a canine showing a very deeply filed labial surface holding seven irregular round gold discs which rest just within the dentine. This illustrates ideal conditions for retention

No. 36 is an incisor with absorption of the root apex, hypercementosis, and a large pulp, conditions indicating infection and early loss of the tooth.

No. 37 is a canine holding a plate attached as previously described. The only new condition here is that the plate has been so deeply polished that the outlines of the pins are exposed. The location of the contact points in this tooth is such that some irregularity of tooth arrangement is indicated. It should be noted in $f i g .2$ that severe abrasion of the incisal edge is the rule.

Spectroscopic analysis ${ }^{24}$ of these discs demonstrated the presence of gold, silver, and copper. One disc from no. 8 and two from no. 43 were used for this analysis. The color and a specific gravity of about 15 indicates a preponderance of gold.

Detailed examination of each specimen, indicates that the holes, although varying from 1 to $2.3 \mathrm{~mm}$. in diameter, were drilled by a cylindrical instrument with a round end or base, and that it was purely by chance that the operator stopped short of the pulp in any instance. The great variety in shape and size of the discs is no doubt accounted for by the fact that they were used more or less as found in nature,

21 Kronfeld, R. 37, 291.

22 Kronfeld, R. 154.

${ }^{23}$ Kronfeld, R. 36.

${ }^{24}$ Analysis made by John Manley, Physics Department, University of Michigan. 


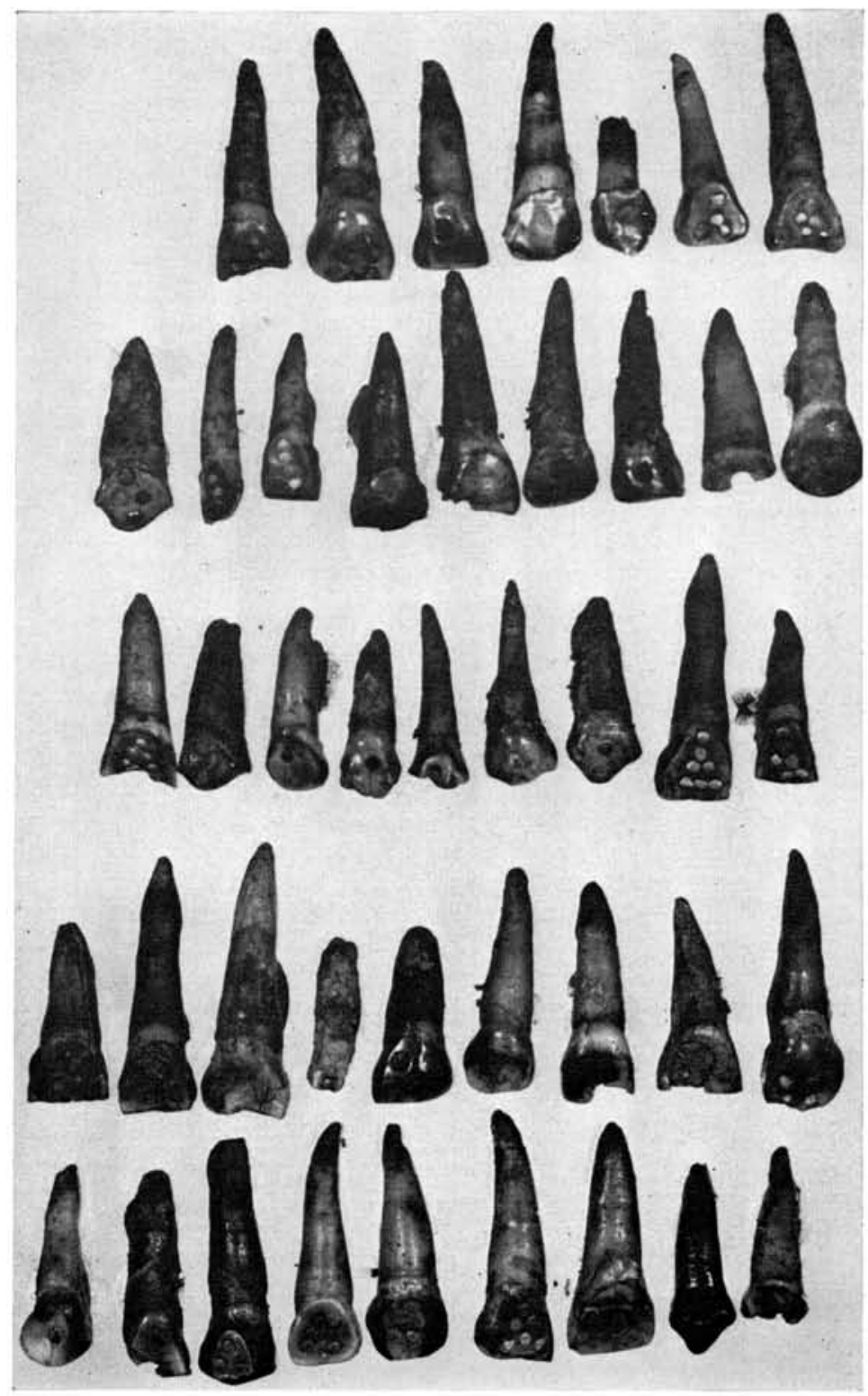

Fig. 1. Teeth numbered from left to right. Top row, 1-7; second row, 8-16; third row, $17-25$; fourth row, $26-34$; last row, 35-43. 


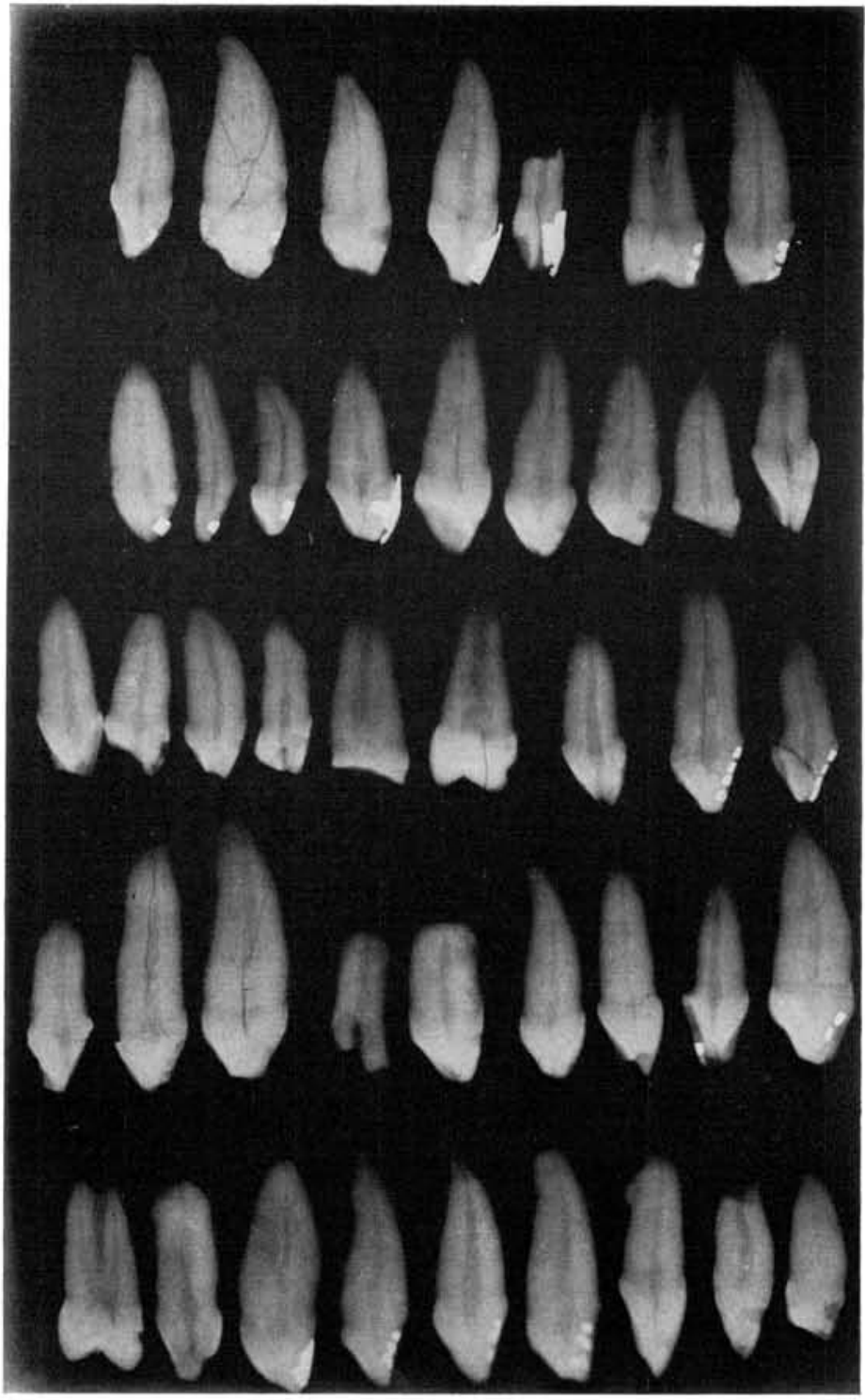

Fig. 2. Teeth numbered from left to right. Top row, 1-7; second row, 8-16; third row, 17-25; fourth row, $26-34$; last row, 35-43. 
TABLE I

Data on teeth and decorations

\begin{tabular}{|c|c|c|c|c|c|c|c|}
\hline \multirow{3}{*}{ rooth no. } & \multirow{3}{*}{ CATALOG NO. } & \multirow{3}{*}{ TOOTH NAME } & \multicolumn{4}{|c|}{ DIAMETERS IN MLLLIMETERS } & \multirow{3}{*}{$\begin{array}{l}\text { PLATE } \\
\text { THICKNES } \\
\text { IN MM. }\end{array}$} \\
\hline & & & \multicolumn{2}{|c|}{ Tooth crown } & \multirow{2}{*}{ Hole } & \multirow{2}{*}{$\begin{array}{c}\text { Gold } \\
\text { disc } \\
\text { average }\end{array}$} & \\
\hline & & & $\begin{array}{l}\text { Mesio-- } \\
\text { distal }\end{array}$ & $\begin{array}{l}\text { Labio- } \\
\text { lingual }\end{array}$ & & & \\
\hline 1 & B $1-123$ & L. C. Incisor & 7.60 & 6.69 & 1.0 & 1.0 & \\
\hline 2 & B $1-123$ & R. Canine & 8.84 & 9.11 & 1.5 & 1.0 & \\
\hline 3 & C $47-10$ & R. C. Incisor & 7.50 & 7.48 & 2.0 & & \\
\hline 4 & C $47-9$ & L. Canine & 7.40 & 7.23 & 1.8 & & 0.15 \\
\hline 5 & C $47-9$ & R. L. Incisor & 5.30 & 5.15 & 1.5 & 1.5 & \\
\hline 6 & C $7-71$ & R. 1st. Prem. & 7.37 & 8.64 & 1.0 & & \\
\hline 7 & C 7.71 & R. Canine & 7.92 & 7.70 & 1.0 & 1.5 & \\
\hline 8 & C 7.71 & L. C. Incisor & 7.88 & 7.11 & 1.2 & 2.0 & \\
\hline 9 & C $7-71$ & L. L. Incisor & 4.29 & 4.40 & 1.2 & 2.0 & \\
\hline 10 & C $7-71$ & R. L. Incisor & 5.86 & 5.83 & & 1.0 & \\
\hline 11 & C 7.71 & L. C. Incisor & 8.50 & 7.25 & 1.6 & 1.0 & 0.33 \\
\hline 12 & C $7-72$ & R. C. Incisor & 8.18 & 8.23 & 1.2 & & \\
\hline 13 & C $7-72$ & L. Canine & 7.64 & 7.80 & 1.0 & & \\
\hline 14 & C $7-72$ & L. Canine & 7.15 & 7.83 & 1.7 & & \\
\hline 15 & C $7-72$ & R. C. Incisor & 7.4 .3 & 7.31 & 2.2 & & \\
\hline 16 & C $7-72$ & R. C. Incisor & 8.56 & 7.00 & 1.8 & & \\
\hline 17 & C $7-72$ & R. C. Incisor & 7.84 & 6.78 & 0.8 & & \\
\hline 18 & C $7-72$ & R. C. Incisor & 7.22 & 6.98 & 2.0 & & \\
\hline 19 & C $7-72$ & L. L. Incisor & 6.20 & 6.58 & 0.9 & & \\
\hline 20 & C $7-72$ & L. L. Incisor & 6.05 & 5.85 & 1.6 & & \\
\hline 21 & C 7.72 & R. 1st. Prem. & 6.18 & 8.33 & 2.2 & & \\
\hline 22 & C $7-72$ & L. 1st. Prem. & 7.20 & 9.30 & 1.9 & & \\
\hline 23 & C $7-74$ & L. C. Incisor & 7.33 & 6.83 & 1.5 & & \\
\hline 24 & G $9-15$ & R. Canine & 7.65 & 7.68 & 1.2 & 1.2 & \\
\hline 25 & G $9-15$ & R. L. Incisor & 6.25 & 6.39 & 1.2 & 1.4 & \\
\hline 26 & G $9-15$ & R. C. Incisor & 7.93 & 6.71 & 0.8 & & \\
\hline 27 & G $9-15$ & L. Canine & 7.71 & 7.97 & 0.8 & & \\
\hline 28 & C $2-19$ & R. Canine & 8.80 & 9.10 & 2.3 & & \\
\hline 29 & C $2-19$ & R. L. Incisor & 6.70 & 6.20 & 2.3 & & \\
\hline 30 & C $2-19$ & L. C. Incisor & 8.12 & 7.98 & 2.0 & & \\
\hline 31 & C $2-19$ & R. Canine & 7.40 & 7.18 & 1.2 & & \\
\hline 32 & C $2-19$ & R. C. Incisor & 7.40 & 7.03 & 1.0 & & \\
\hline 33 & C $2-19$ & R. C. Incisor & 8.60 & 7.15 & 1.0 & 1.0 & \\
\hline 34 & C $2-19$ & L. Canine & 8.42 & 9.10 & 1.5 & 1.5 & \\
\hline 35 & C $2-19$ & R. 1st. Prem. & 7.11 & 9.00 & 1.7 & & \\
\hline 36 & C $2-19$ & L. C. Incisor & 7.40 & 7.00 & 1.8 & & \\
\hline 37 & C $2-19$ & R. Canine & 7.98 & 8.20 & 1.0 & 1.0 & 0.10 \\
\hline 38 & C $2-19$ & L. Canine & 7.49 & 7.50 & 1.0 & & \\
\hline 39 & C $2-19$ & R. Canine & 8.04 & 8.00 & 1.4 & 1.4 & \\
\hline 40 & C $2-19$ & R. Canine & 7.96 & 8.12 & 1.4 & 1.4 & \\
\hline 41 & C $2-19$ & L. C. Incisor & 8.75 & 8.21 & 2.2 & & \\
\hline 42 & C $2-19$ & L. L. Incisor & 7.65 & 6.50 & 2.0 & & \\
\hline 43 & C $2-19$ & R. L. Incisor & 6.70 & 6.43 & 1.0 & 1.0 & \\
\hline
\end{tabular}




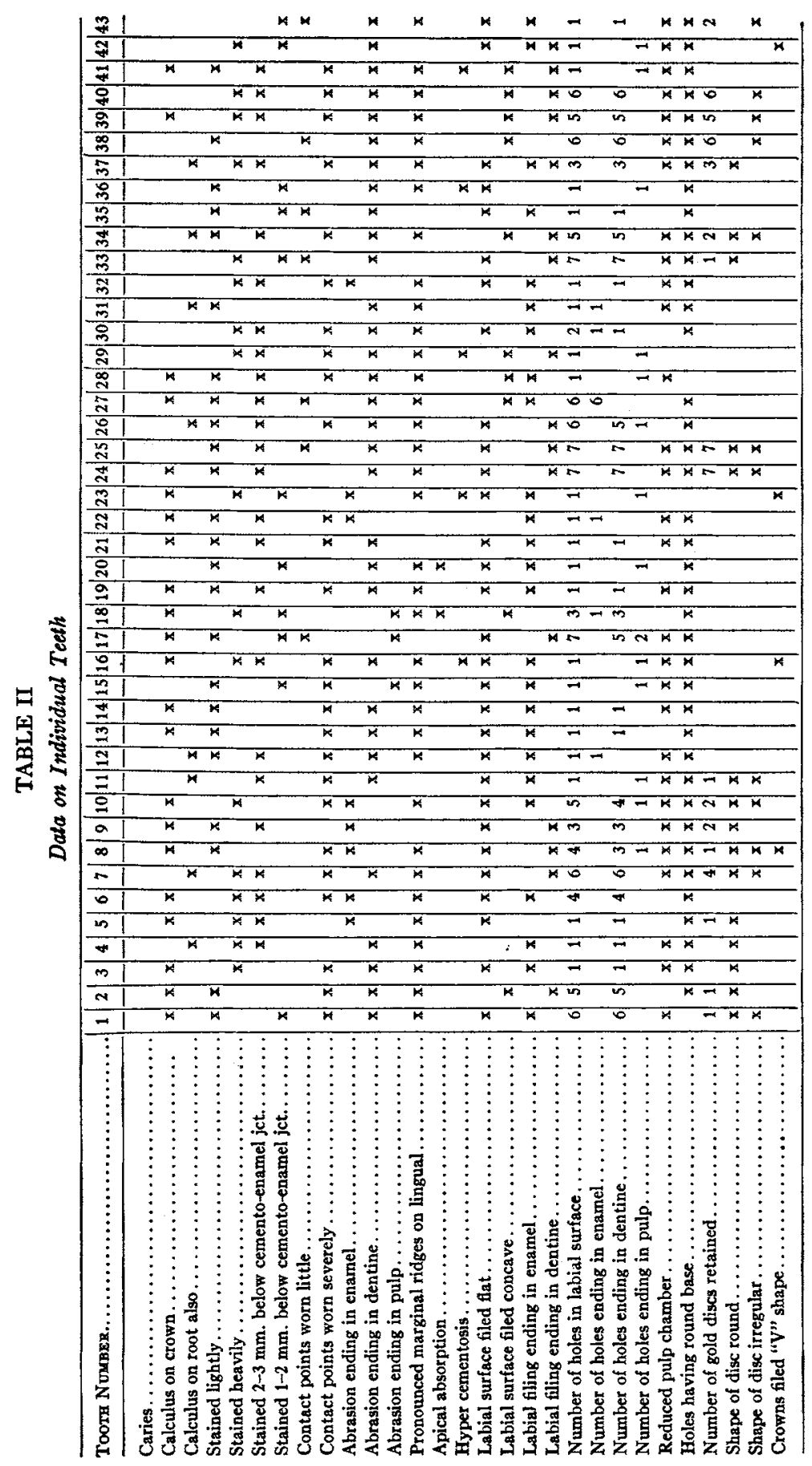


and were not subjected to any preparation beyond the possible selection of one of approximate size. There is every reason to believe that the Filipinos obtained the gold used in this manner by placer mining in some of the Philippine streams, from which gold may be obtained today. Judging from the flanges on the labial sides of the disc, and the absence of anything to indicate an auxiliary attachment other than mechanical, one may assume that the discs were simply hammered into the holes. Retention in many cases was made doubly easy because the hole was larger at the base than at the surface. The locations of concretions point to gingival recession ${ }^{25}$ in at least 20 per cent of the teeth. The distribution of stains indicates marginal gingivitis in at least 70 per cent. Many of the pulps were exposed during the operation of drilling holes. Furthermore, there is evidence that suppurative conditions existed in a number of instances. The extreme wear of incisal edges and contact points implies excessive movement, probably associated with chewing of betel nut and of harsh and gritty food. The presence of salivary deposits on all surfaces of the teeth suggests that this chewing was the total extent of any oral hygiene practiced. One tooth (no. 37) illustrates malocclusion of the anterior teeth. No. 9 shows the presence of a common variation in form. Nos. 2, 8, and 22 indicate the presence of pyorrhetic conditions accompanied, in no. 2, by severe alveolar absorption. Despite the fact that not a single instance of caries was found in this collection, other pathological conditions present indicate that these people lost their decorated teeth early.

The evidence presented demonstrates that these inlaid decorative discs were attached by a partial combination of the modern gold foil filling and cast inlay methods. There is nothing to indicate that the discs and plates were for any other purpose than decoration, inasmuch as no disc occurs where it could not be seen; and, because of the total absence of caries, no need for restorative measures could have existed.

\section{REFERENCES TO LITERATURE}

(1) Blatr, Ema Helen and Robertson, J. A. The Philippine Islands; 1493-1898, 55 vols. Cleveland, 1903-1909.

(2) Davis, J. B. Thesaurus Craniorum; Catalogue of the Skulls of the various Races of Man, in the collection of J. B. Davis. London, 1867.

${ }^{25}$ Kronfeld, R. 303. 
(3) Furness, W. H., 3RD The Home-life of Borneo Headhunters. Philadelphia, 1902.

(4) Gomes, E. H. Seventeen Years among the Sea Dyaks of Borneo. London, 1911.

(6) Kronferd, R. Histopathology of the Teeth and their Surrounding Structures, Philadelphia, 1933.

(7) MaAs, Aufred Durch Central-Sumatra. 2 vols.

(8) Nefring, H. voN Zeit. Eihnol. 14: 1882.

(9) Rippen, Bene van 1. Den. Cosmos 59:861, 1917.

2. J. Allied Den. Soc. 13: 1, 1918.

3. J. Allied Den. Soc. 13: 219, 1918.

4. J. Allied Den. Soc. 13: 365, 1918.

(10) Roтн, H. L. The Natives of Sarawak and British North Borneo. 2 vols. New York, 1896.

(11) Savilie, M. H. Amer. Anthrop. 15: 377, 1913. 